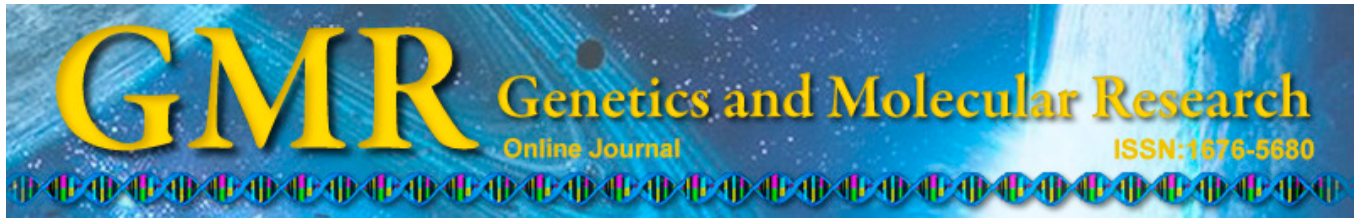

\title{
Isolation and characterization of polymorphic microsatellite loci from Zelkova schneideriana Hand.-Mazz.
}

\author{
H.L. Liu ${ }^{1,2}$, R.Q. Zhang ${ }^{1}$, M.L. Geng ${ }^{3}$, J.Y. Zhu ${ }^{1,2}$ and J.L. Ma ${ }^{1,2}$ \\ ${ }^{1}$ College of Forestry, Central South University of Forestry and Technology, \\ Changsha, Hunan, China \\ ${ }^{2}$ Forestry Research Institute of Guangxi Zhuang Autonomous Region, \\ Nanning, Guangxi, China \\ ${ }^{3}$ Institute of Botany, Jiangsu Province and Chinese Academy of Sciences, \\ Nanjing, Jiangsu, China \\ Corresponding author: R.Q. Zhang \\ E-mail: hanszhangriqing@csuft.edu.cn
}

Genet. Mol. Res. 13 (4): 10062-10066 (2014)

Received May 6, 2014

Accepted September 24, 2014

Published December 3, 2014

DOI http://dx.doi.org/10.4238/2014.December.3.1

\begin{abstract}
Zelkova schneideriana is a highly valued hardwood species. An improved technique for isolating codominant compound microsatellite markers was used to develop simple sequence repeat markers for Z. schneideriana. A total of 12 microsatellite loci were identified. Overall, the number of alleles per locus ranged from 8-19, with an average of 11.75. Observed heterozygosity and expected heterozygosity values ranged from $0.109-0.709$ and $0.832-0.929$, respectively. Polymorphic information content is from $0.803-0.915$, with an average of 0.854 . These markers will be very important for future research related to the genetic diversity, population structure, patterns of gene flow, and mating system of this species.
\end{abstract}

Key words: Genetic diversity; Microsatellite loci; Simple sequence repeat; Zelkova schneideriana Hand.-Mazz. SSRs 


\section{INTRODUCTION}

Zelkova schneideriana Hand.-Mazz. is the second-most state-protected plant species; it is a deciduous hardwood tree that belongs to the genus Ulmus. Zelkova produces excellent timber and shows massive, hard, sheeny, and durable features (Zhang et al., 2011). $Z$. schneideriana is also one of the most important landscape species because of its large crown and with paler green in spring and orange or rusty red leaves in the autumn (Cao et al., 2005). This species is highly valued in China, Korea, Japan, and other East Asian countries (Lo et al., 1995). However, it has become a rare and endangered species in China because of uncontrolled commercial logging and the lack of effective propagation methods (Fu and Jin, 1992). Currently, most of the efforts have been focused on the breeding and cultivation of this species. Studies of the genetic diversity, population ecology, and conservation of $Z$. schneideriana are insufficient and limited (Liu et al., 2005), making the development of genetic markers in Z. schneideriana very important.

Microsatellite markers are highly polymorphic, abundant, and relatively evenly distributed throughout eukaryotic genomes, and thus can be used as co-dominant markers. The popularity of these markers is related to their ease of amplification by polymerase chain reaction (PCR), their co-dominant nature, and their typically high levels of allelic diversity at different loci (Arif et al., 2011). The dual-suppression-PCR technique was recently developed. By applying this technique, Lian et al. (2006) developed simple sequence repeat (SSR) markers for more than 30 species. This technique for isolating codominant compound microsatellite markers was used to develop SSR markers for Z. schneideriana in this study.

\section{MATERIAL AND METHODS}

Three diploid populations of Z. schneideriana plants, including Anhui population (AH), Jiangxi population (JX), and United States population (US) were collected. Voucher specimens for the sampled populations were deposited in the herbarium from Forestry Research Institute of Guangxi Zhuang Autonomous Region. Genomic DNA was extracted from silica-gel-dried leaves using a modified hexadecyltrimethylammonium bromide method (Doyle, 1991). One individual from the AH population was selected for digestion with the EcoRV restriction enzyme (Takara, Dalian, China) for construction of a DNA library for $Z$. schneideriana. After digestion, the fragments were ligated to a specific unequal-length adaptor (consisting of an upper strand 5'-GTA ATA CGA CTC ACT ATA GGG CAC GCG TGG TCG ACG GCC CGG GCT GGT-3' and a lower strand, with the 3' end-capped with an amino residue: 5'-ACC AGC CC-3') by T4 DNA ligase (Takara). Subsequently, the fragments were PCR-amplified from the EcoRV DNA library using the compound SSR primer $(\mathrm{AC})_{6}(\mathrm{AG})_{5}$ or $(\mathrm{TC})_{6}(\mathrm{AC})_{5}$ and an $\mathrm{AP}_{2}$ adaptor (5'-CTA TAG GGC ACG CGT GGT-3'). Each 50- $\mu$ L PCR contained 30-50 ng genomic DNA, of 1X PCR buffer with $\mathrm{MgCl}_{2}, 0.2 \mathrm{mM}$ of each dNTP, 0.5 U Taq polymerase (Takara), and $0.5 \mathrm{mM}$ of each compound SSR primer and $\mathrm{AP}_{2}$. The PCR amplification conditions were as follows: 1 cycle for $9 \mathrm{~min}$ at $94^{\circ} \mathrm{C}, 30 \mathrm{~s}$ at $62^{\circ} \mathrm{C}$, and $1 \mathrm{~min}$ at $72^{\circ} \mathrm{C} ; 5$ cycles each for $30 \mathrm{~s}$ at $94^{\circ} \mathrm{C}, 30 \mathrm{~s}$ at $62^{\circ} \mathrm{C}$, and $1 \mathrm{~min}$ at $72^{\circ} \mathrm{C} ; 35 \mathrm{cycles}$ each of $30 \mathrm{~s}$ at $94^{\circ} \mathrm{C}, 30 \mathrm{~s}$ at $60^{\circ} \mathrm{C}$, and $1 \mathrm{~min}$ at $72^{\circ} \mathrm{C}$; ending with a final cycle of $30 \mathrm{~s}$ at $94^{\circ} \mathrm{C}, 30 \mathrm{~s}$ at $60^{\circ} \mathrm{C}$, and 9 min at $72^{\circ} \mathrm{C}$. The products were purified using a DNA clean-up kit (Axygen, Union City, CA, USA) and transformed into competent JM109 cells (Takara) after ligation with the pMD 18-T vector (Takara). A single clone was evaluated using the $\mathrm{M}^{+}{ }^{+}$(5'-TGT AAA ACG 
ACG GCC AGT-3')/M13- (5'-CAG GAA ACA GCT ATG ACC-3') universal primers. Positive clones were obtained and sequenced on an ABI Prism 3730 automated DNA sequencer (Applied Biosystems, Foster City, CA, USA). Specific primers were designed based on sequences flanking the compound SSR primers using Primer Premier 5.0 (Clarke and Gorley, 2001).

To examine the effectiveness and polymorphism of the primers, 20 individuals of $Z$. schneideriana from the AH population, 23 individuals from the JX population, and 12 individuals from the US population were collected. To evaluate polymorphism levels, compound SSR primers were labeled with fluorescent dyes (6-FAM or HEX). Amplified products were analyzed by fluorescence capillary electrophoresis on an ABI Prism 3730 automated DNA sequencer (Applied Biosystems). The data were compiled and scored using GeneMaker 2.2.0 (Soft-Genetics, State College, PA, USA). Cervus 2.0 (Kalinowski et al., 2007) was used to calculate number of alleles per locus $\left(N_{\mathrm{A}}\right)$, observed heterozygosity $\left(H_{\mathrm{O}}\right)$, expected heterozygosity $\left(H_{\mathrm{E}}\right)$, and polymorphic information content (PIC). Genepop (http://genepop.curtin.edu. $\mathrm{au} /$ ) was employed to test the Hardy-Weinberg equilibrium and linkage disequilibria.

\section{RESULTS}

A total of 12 polymorphic microsatellite loci were identified (Table 1). $N_{\mathrm{A}}$ per locus ranged from 6-11 in the US population, with an average of 8.58 alleles per locus. $H_{\mathrm{O}}$ ranged from $0.167-0.667$, with an average of $0.341 . H_{\mathrm{E}}$ values ranged from 0.681-0.917, with an average of 0.851 . The PIC of the 12 microsatellite loci ranged from 0.602-0.866, with an average of 0.794 . In the JX population, $N_{\mathrm{A}}$ per locus ranged from 7-15, with an average of 10.42 alleles per locus. $H_{\mathrm{O}}$ ranged from $0.043-0.870$, with an average of $0.471 . H_{\mathrm{E}}$ values ranged from $0.815-0.929$, with an average of 0.879 . The PIC ranged from $0.768-0.901$, with an average of $0.843 . N_{\mathrm{A}}$ per locus ranged from 7-16 in the AH population, with an average of 9.25 alleles per locus. $H_{\mathrm{O}}$ ranged from $0.150-0.700$, with an average of $0.417 . H_{\mathrm{E}}$ values ranged from $0.790-0.935$, with an average of 0.849 . The PIC ranged from $0.736-0.905$, with an average of 0.805 (Table 2). Most of microsatellite loci deviated significantly from HardyWeinberg equilibrium $(\mathrm{P}<0.001)$. Pairwise linkage disequilibrium between the 12 pairs of loci was not significant $(\mathrm{P}<0.001)$.

Table 1. Characterization of 12 microsatellite loci in Zelkova schneideriana Hand.-Mazz.

\begin{tabular}{|c|c|c|c|c|c|c|c|c|c|c|}
\hline Locus & $\begin{array}{l}\text { Forward primer } \\
\text { sequence }\left(5^{\prime}-3^{\prime}\right)\end{array}$ & Reverse primer sequence (5'-3') & $\begin{array}{l}\text { Repeat } \\
\text { motif }\end{array}$ & $\begin{array}{l}\text { TA } \\
\left({ }^{\circ} \mathrm{C}\right)\end{array}$ & $\begin{array}{l}\text { Size } \\
\text { (bp) }\end{array}$ & $N_{\mathrm{A}}$ & $H_{\mathrm{O}}$ & $H_{\mathrm{E}}$ & PIC & $\begin{array}{c}\text { Accession } \\
\text { No. }\end{array}$ \\
\hline ZsSSR1 & $(\mathrm{AC})(\mathrm{AG})_{5}$ & GGTGATAAAGGCAAGTAATAGA & $(\mathrm{AC})(\mathrm{AG})_{5}$ & 51.7 & 161 & 9 & 0.545 & 0.837 & 0.809 & KJ749829 \\
\hline ZsSSR2 & $(\mathrm{AC})_{6}(\mathrm{AG})_{5}$ & ATCAGGGAACTCAGCCAC & $(\mathrm{AC})_{6}(\mathrm{AG})_{5}$ & 51.9 & 109 & 11 & 0.491 & 0.874 & 0.852 & KJ749830 \\
\hline ZsSSR3 & $(\mathrm{AC})_{6}(\mathrm{AG})_{5}$ & GCTTAGGGCAGACTCATA & $(\mathrm{AC})_{6}(\mathrm{AG})_{16}$ & 47.6 & 260 & 14 & 0.273 & 0.917 & 0.902 & KJ749831 \\
\hline ZsSSR4 & $(\mathrm{AC})_{6}(\mathrm{AG})_{5}$ & CGGGGCTGGTATCTTGTA & $(\mathrm{AC})_{6}(\mathrm{AG})_{27}$ & 53.8 & 125 & 12 & 0.618 & 0.869 & 0.846 & KJ749832 \\
\hline ZsSSR5 & $(\mathrm{AC})_{6}(\mathrm{AG})_{5}^{5}$ & CAGCCATGAGCCAGAAAT & $(\mathrm{AC})_{6}(\mathrm{AG})_{6}$ & 53.6 & 254 & 19 & 0.709 & 0.929 & 0.915 & KJ749833 \\
\hline ZsSSR6 & $(\mathrm{AC})_{6}(\mathrm{AG})_{5}^{5}$ & AAAGGTGATAAAGGCAAG & $(\mathrm{AC})_{6}(\mathrm{AG})_{5}$ & 47.3 & 164 & 16 & 0.564 & 0.923 & 0.908 & KJ749834 \\
\hline ZsSSR7 & $(\mathrm{AC})_{6}(\mathrm{AG})_{5}$ & CGTCCAAGAAATCTCACA & $(\mathrm{AC})_{6}(\mathrm{AG})_{5}$ & 48.3 & 135 & 11 & 0.400 & 0.893 & 0.874 & KJ749835 \\
\hline ZsSSR8 & $(\mathrm{AC})_{6}(\mathrm{AG})_{5}$ & AAGGGAAGATGAAGTGGAGA & $(\mathrm{AC})_{6}(\mathrm{AG})_{12}^{3}$ & 53.4 & 182 & 12 & 0.309 & 0.865 & 0.842 & KJ749836 \\
\hline ZsSSR9 & $(\mathrm{AC})_{6}(\mathrm{AG})_{5}^{3}$ & CAAGTTGCACATTCATTCAG & $(\mathrm{AC})_{6}(\mathrm{AG})_{5}$ & 51.8 & 131 & 10 & 0.327 & 0.859 & 0.834 & KJ749837 \\
\hline ZsSSR10 & $(\mathrm{AC})_{6}(\mathrm{AG})_{5}$ & CTTATTCAAGCTGGAGCA & $(\mathrm{AC})_{6}(\mathrm{AG})_{9}$ & 48.8 & 273 & 9 & 0.109 & 0.871 & 0.848 & KJ749838 \\
\hline ZsSSR11 & $(\mathrm{AC})_{6}(\mathrm{AG})_{5}$ & CCAAACAAATCCACCTAAA & $(\mathrm{AC})_{6}(\mathrm{AG})_{5}$ & 50.9 & 162 & 8 & 0.509 & 0.841 & 0.814 & KJ749839 \\
\hline ZsSSR 12 & $(\mathrm{AC})_{6}(\mathrm{AG})_{5}$ & TGAGTTGTCAGAAGAGGG & $\begin{array}{l}(\mathrm{AC})_{6}(\mathrm{AG})_{7} \\
(\mathrm{AC})_{5}(\mathrm{AC})_{5} \\
(\mathrm{AG})_{5}\end{array}$ & 47 & 113 & 10 & 0.218 & 0.832 & 0.803 & KJ749840 \\
\hline
\end{tabular}

TA annealing temperature. 
Table 2. Results of initial primer screening in 3 populations of Zelkova schneideriana Hand.-Mazz.

\begin{tabular}{|c|c|c|c|c|c|c|c|c|c|c|c|c|}
\hline \multirow[t]{2}{*}{ Locus } & \multicolumn{4}{|c|}{ United States $(\mathrm{N}=12)$} & \multicolumn{4}{|c|}{ Jiangxi $(\mathrm{N}=23)$} & \multicolumn{4}{|c|}{ Anhui $(\mathrm{N}=20)$} \\
\hline & $N_{\mathrm{A}}$ & $H_{\mathrm{O}}$ & $H_{\mathrm{E}}$ & PIC & $N_{\mathrm{A}}$ & $H_{\mathrm{O}}$ & $H_{\mathrm{E}}$ & PIC & $N_{\mathrm{A}}$ & $H_{\mathrm{O}}$ & $H_{\mathrm{E}}$ & PIC \\
\hline ZsSSR1 & 8 & 0.333 & 0.837 & $0.778 * * *$ & 9 & 0.565 & 0.861 & $0.823 * * *$ & 7 & 0.650 & 0.823 & $0.777^{\text {n.s. }}$ \\
\hline ZsSSR2 & 8 & 0.417 & 0.859 & $0.801 *$ & 9 & 0.522 & 0.897 & $0.864 * * *$ & 9 & 0.500 & 0.827 & $0.781 * * *$ \\
\hline ZsSSR3 & 10 & 0.167 & 0.906 & $0.855 * * *$ & 13 & 0.217 & 0.907 & $0.878 * * *$ & 10 & 0.400 & 0.910 & $0.877 * * *$ \\
\hline ZsSSR4 & 9 & 0.500 & 0.895 & $0.842 *$ & 12 & 0.870 & 0.901 & $0.871^{*}$ & 7 & 0.400 & 0.790 & $0.736 * * *$ \\
\hline ZsSSR5 & 10 & 0.667 & 0.917 & $0.866 * * *$ & 15 & 0.739 & 0.929 & $0.901^{*}$ & 16 & 0.700 & 0.935 & $0.905 * *$ \\
\hline ZsSSR6 & 8 & 0.417 & 0.830 & $0.768 * * *$ & 13 & 0.652 & 0.925 & $0.897 * *$ & 14 & 0.550 & 0.919 & $0.888 * * *$ \\
\hline ZsSSR7 & 8 & 0.167 & 0.866 & $0.809 * * *$ & 9 & 0.478 & 0.883 & $0.848 * * *$ & 9 & 0.450 & 0.883 & $0.846 * * *$ \\
\hline ZsSSR8 & 11 & 0.417 & 0.891 & $0.841 * * *$ & 11 & 0.391 & 0.887 & $0.855^{* * *}$ & 8 & 0.150 & 0.821 & $0.773 * * *$ \\
\hline ZsSSR9 & 8 & 0.167 & 0.855 & $0.797 * * *$ & 9 & 0.435 & 0.834 & $0.792 * * *$ & 9 & 0.300 & 0.804 & $0.754 * * *$ \\
\hline ZsSSR10 & 9 & 0.167 & 0.906 & $0.854 * * *$ & 8 & 0.043 & 0.867 & $0.829 * * *$ & 7 & 0.150 & 0.794 & $0.742 * * *$ \\
\hline ZsSSR11 & 6 & 0.417 & 0.681 & $0.602 *$ & 7 & 0.522 & 0.815 & $0.768 * * *$ & 7 & 0.550 & 0.841 & $0.795 * *$ \\
\hline ZsSSR12 & 8 & 0.250 & 0.768 & $0.712 * * *$ & 10 & 0.217 & 0.836 & $0.794 * * *$ & 8 & 0.200 & 0.836 & $0.790 * * *$ \\
\hline Mean & 8.58 & 0.341 & 0.851 & 0.794 & 10.42 & 0.471 & 0.879 & 0.843 & 9.25 & 0.417 & 0.849 & 0.805 \\
\hline
\end{tabular}

$\mathrm{N}$ sample size for each population. $* * *$ and $* * *$ Significant departures from Hardy-Weinberg equilibrium at $\mathrm{P}<$ $0.05, \mathrm{P}<0.01, \mathrm{P}<0.001$, respectively. n.s. $=$ not significant.

\section{DISCUSSION}

All novel microsatellite loci identified in Z. schneideriana in the present study showed high levels of polymorphism, indicating that these markers will significantly influence future studies related to the genetic diversity, population structure, patterns of gene flow, and mating system of this species.

\section{ACKNOWLEDGMENTS}

Research supported by the National Forestry Public Welfare Industry Research Project "Provenance Selection and Rapid Propagation in Zelkova schneideriana" (grant \#200904011); the Guangxi Youth Fund Project "Fine-scale genetic structure of Zelkova schneideriana: Based on evidence from population of Yachang Nature Reserve in Guangxi revealed by SSR Markers" (grant \#2013GXNSFBA019093); and the Project from Guangxi Key Laboratory of Superior Timber Trees Resource Cultivation "Genetic Diversity of Zelkova schneideriana from Different Provenance by ISSR Analysis and Organ Tissue Culture of Zelkova schneideriana" (grant \#12B0301).

\section{REFERENCES}

Arif IA, Khan HA, Bahkali AH, Al Homaidan AA, et al. (2011). DNA marker technology for wildlife conservation. Saudi J. Biol. Sci. 18: 219-225.

Cao YF, Liu ZH and Zhao HE (2005). Preliminary investigation on the suitability of some deciduous broad-leaved trees in Beijing. J. Chin. Landscape Archit. 8: 62-66.

Clarke KR and Gorley RN (2001). Primer v5: User manual/tutorial. Primer-E Ltd., Plymouth, UK.

Doyle JJ (1991). DNA protocols for plants. In: Molecular techniques in Taxonomy (Hewitt GM and Johnston A eds.). Springer-Verlag, Berlin.

Fu LG and Jin JM (1992). Plants Red Book of China-Rare and Endangered Plants: Volume I. Science Press, Beijing, 64-65.

Kalinowski ST, Taper ML, Marshall TC (2007). Revising how the computer program CERVUS accommodates genotyping error increases success in paternity assignment. Mol. Ecol. 16: 1099-1106.

Lian C, Abdul Wadud M, Geng Q, Shimatani K, et al. (2006). An improved technique for isolating codominant compound 
microsatellite markers. J. Plant. Res. 119: 415-417.

Liu XC, Li YY and Chen SY (2005). Genetic diversity of Zelkova schneideriana from different provenance by ISSR analysis. J. West China For. Sci. 34: 43-47.

Lo CN, Chung HH and Chiu CM (1995). Effects of pruning on the growth and the branch occlusion tendency of Taiwan Zelkova (Zelkova serrata Hay.) young plantations. Bull. Taiwan For. Res. Inst. 10: 315-323.

Zhang RQ, Yang J., Jin XL, Tang CF, et al. (2011). Dynamic activity of endogenous plant hormones in Zelkova schneideriana during the growth of seedlings. Nonwood Forest Research 29: 1-5. 